\title{
CULTURAL DUE DILIGENCE IN M\&A. IMPORTANCE OF SOFT RISKS FACTORS
}

\author{
Iulian WARTER, Ph.D. ${ }^{1}$, Liviu WARTER ${ }^{2}$, Ph.D. \\ ${ }^{1}$ Center for Socio-Economic Studies and Multiculturalism, Iasi, Romania, \\ Tel.: 0372-765-122, E-mail: iulian@warter.ro \\ ${ }^{2}$ Center for Socio-Economic Studies and Multiculturalism, Iasi, Romania, \\ Tel.: 0372-765-122, E-mail: liviu@warter.ro
}

\begin{abstract}
During the last decades, the corporate world has witnessed a significant rise in the number of cross border mergers and acquisitions (M\&As).

In cross border M\&As, not only different corporate cultures collide, but also different professional and national cultures.

The purpose of Cultural Due Diligence (CDD) is to get a coherent image of the intercultural challenges of the $M \& A$ in order to be aware of the intercultural risks and opportunities.

This article aims to reveal the perception of managers involved in the pre$M \& A$ stage on the soft risks factors that need to be investigated during CDD.

This study proposes an appraisal of the most important intercultural issues that need to be considered in $M \& A$.

Our contribution to the intercultural aspects of $M \& A$ literature consists in improving the current understanding of Cultural Due Diligence content.
\end{abstract}

Keywords: mergers and acquisitions (M\&As); cultural due diligence; national culture; organizational culture; professional culture.

JEL Classification: $\mathrm{F}_{23}, \mathrm{G}_{34}, \mathrm{M}_{14}, \mathrm{Z}_{19}$.

\section{Introduction}

M\&A is one of the most important ways for corporate development. Cross border M\&A is also maybe the most important vehicle for foreign direct investment (FDI). M\&A is very suitable to today's rapidly developing global business environment. Moreover, despite the past years of crisis, M\&A's have not declined. On the contrary, it can be noticed an increase in M\&A activity. 

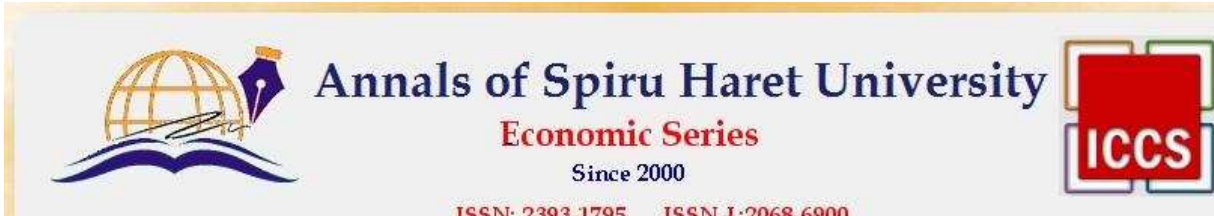

ISSN: $2393-1795$ ISSN-I.2068-6900

Issue $2 / 2017$

Although in the last twenty years, there has been a growing body of research on the success factors of mergers and acquisitions, the key determinants for success remain poorly understood.

The core of this paper is the pre-M\&A stage. A better understanding of the impact of national, organizational and professional cultures in M\&A is the primary purpose of the research process.

The almost general opinion is that M\&A is one of the most important business phenomena in the past decades and it will be in the future too. But this does not prevent scholars and practitioners to warn about the M\&A dangers.

The common underlying belief is that intercultural aspects have a strong influence on M\&A performance. Ergo researchers have to bridge the gap between theory and practice and to be more realistic and less reductionist in an interdisciplinary approach.

Cultural diversity might be both an asset and a liability in organizations. Whether the losses associated with cultural diversity can be minimized and the gains be realized will depend likewise on the managers' ability to manage the M\&A processes.

Due diligence is a comprehensive appraisal of a business undertaken by a prospective buyer, especially to establish its assets and liabilities and evaluate its commercial potential.

Cultural Due Diligence (CDD) is a diagnostic process conducted to ascertain the degree of cultural alignment or compatibility between companies that are party to a merger or acquisition. It is used to develop an effective integration/alignment plan to deal with the impact of culture on the merger or acquisition.

Notwithstanding most of the researchers highlight the importance of due diligence in M\&A, in many cases there is not an appropriate practical approach. Cultural Due Diligence (CDD) intends to offer data enough detailed to determine potential areas of culture clash. The impact of cultural diversity rest on the managers' ability to manage the negotiations and due diligence processes in an effective manner.

The present research is part of a study involving a consideration of national, organizational and professional cultures as a factor to maximize the efficiency of negotiations, decision-making and due diligence.

The study explores the problematic cultural aspects of the pre-M\&A stage in order to achieve a better understanding of the cultural issues related to negotiation, decision-making, and due diligence. A more profound clarification of the influence 


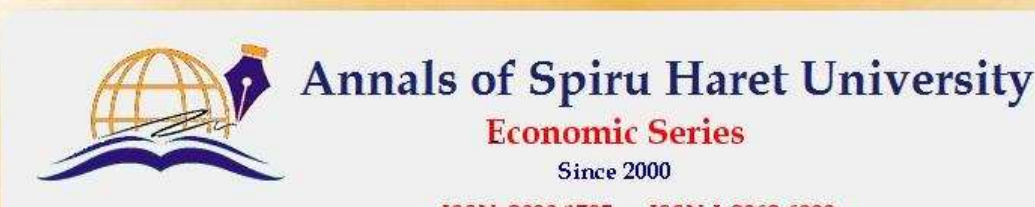

ISSN: 2393-1795 ISSN-L:2068-6900

Issue 2/2017

of national, organizational and professional cultures in mergers and acquisitions is the main purpose of the research process.

The cultural specificity of the managers involved in M\&As is not considered exclusively given by their national culture. They are identified culturally by the following categories: nationality, ethnicity, native language, foreign languages, profession, gender, job level, level of education. Their perception is considered also to be influenced by their position (role) in negotiation/decision/due diligence.

The attributes of the participants in the pre-M\&A stage are considered to be a result of a mix between national, organizational and professional culture.

Although most of the researchers point to the importance of due diligence in M\&A, in many cases there is not an appropriate practical approach. It can be stated that M\&A research has underestimated the roles of individual managers and employees. Individuals' mind-sets and interests influence the due diligence, negotiation, decision processes and the integration of the companies. It has to be emphasised that due diligence's importance lies in determining the acceptable level of change within a company.

This study uses Factor Analysis to extract a dimension and the component factors starting from the following basic items: Communication, Organizational culture, National culture, and Professional culture.

\section{Literature review}

\subsection{Mergers and acquisitions}

Trompenaars and Asser (2010) consider that global business expansion and development through mergers, acquisitions and strategic alliances is big business. Another interesting remark on this topic is offered by Sahoo, Nataraj and Dash (2014). They argue that FDI, defined in accordance with International Monetary Fund (IMF) guidelines, can take the form of greenfield investment in a new establishment or merger and acquisition of an existing local enterprise. One can emphasise that business is increasingly pursuing mergers and acquisitions, also as a consequence of other factors such as political, monetary etc.

International business scholars and practitioners have postulated that, for firms that conduct business abroad, costs arise from the unfamiliarity of the environment that is, the cultural, geographic, and institutional distance involved - and sometimes even from a perceived lack of legitimacy; thus foreignness is a liability for the investing firm [Bertrand \& Capron, 2015; Angwin \& Meadows, 2014].

Others posit that cross-border mergers and acquisitions have become an important strategy employed by firms in the global competitive landscape [Hitt \& 40 


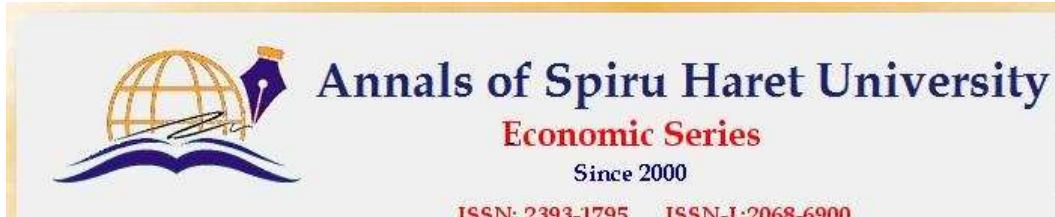

ISSN: $2393-1795$ ISSN-I.2068-6900

Issue $2 / 2017$

Pisano, 2003]. As such, managers must be better informed as to the potential opportunities and challenges presented by this significant strategic action. Furthermore, they must understand how to increase the probability of successful cross-border M\&A actions. Finally, there is evidence that the gainers of tomorrow are presumably to be anti-cyclical acquirers of today, as the M\&A wave in the 90's proved [Warter \& Warter, 2015].

1Others [Weber, Rachman-Moore \& Tarba, 2012; Gomes et al., 2013] indicate that much has been written about the financial, strategic, and integration aspects of M\&A, but the findings are contradictory and the reasons for variations in M\&A performance have remained unclear, probably because of the focus on premerger variables, thereby neglecting cross-cultural conflicts between people in the post-merger period.

One of the enduring paradoxes in M\&A activity has been the propensity of corporations and executives to engage in M\&As despite consistent evidence that post-merger performance of acquiring firms is disappointing [Zhang et al., 2014]. A possible explanation to this paradox is that existing knowledge on M\&As provides a limited and insufficient understanding of different parts of this important phenomenon, although the high emphasis on surveys clearly indicates a preference in gaining more pragmatic knowledge of strategic alliance activity by studying firms in realistic as opposed to simulated contexts [for a review, see Gomes, Barnes \& Mahmood, 2016].

One of the major shortcomings in the research of M\&A performance is revealed by Weber, Tarba and Reichel (2011). The authors point out that the combined effects of corporate culture, national culture, and synergy potential on various integration approaches, as well as their influence on M\&A performance, have never been simultaneously investigated.

The emerging picture shows a lack of consensus about the M\&A particularities. On the same time, the common underlying belief is that intercultural aspects have a strong influence on M\&A performance. Researchers have to bridge the gap between theory and practice. Practitioners must focus on action-oriented thinking and encourage theoreticians to be more realistic and less reductionist in an interdisciplinary approach.

In addition to the previous ascertainment, maybe the most important problem is the misunderstanding of the M\&A performance concept itself. Do these findings point to a need for M\&A scholars to deepen the research? The answer is a clear yes. There are many gaps and unsolved problems in the field that require more theoretical and empirical study. 


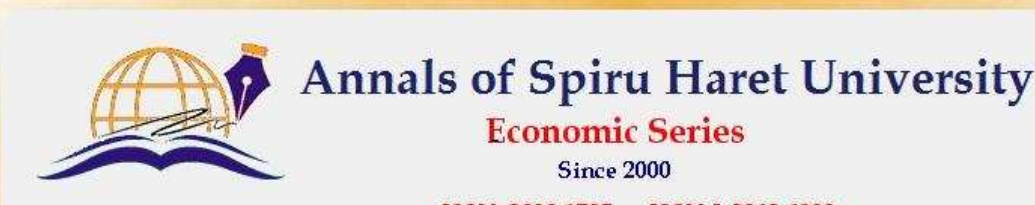

ISSN: 2393-1795 ISSN-L:2068-6900

Issue 2/2017

Trompenaars and Asser (2010) point out that although success rates of mergers and acquisitions are difficult to compare, as surveys in the area use a variety of assessment metrics, most point to a success rate of about one third, while some have found that only $20 \%$ of mergers and acquisitions are ultimately successful. Analysis of the success rate of mergers and acquisitions are available [ed. Rosenbloom, 2002] and show that value creation, the ultimate aim of a merger, acquisition, joint venture, or related type deal, is anything but certain. One in five such deals falls through after it's announced.

It can be concluded that the central issue in M\&A remains the high rate of failure. Even the "biggest proponents" of M\&A admit that this activity has uncertain outcomes. Reasons for failure remain poorly understood by scholars and practitioners. There is a need to learn more about this issue and this research is directed toward this aim.

The findings show that mergers conducted within a merger wave show less quality and more uncertainty as compared to mergers realized outside a wave. Since the bias reduction is related to the pre-acquisition period it could be possible that the treated firms increase their export orientation with ownership change, but this is also not the case since estimates for the impact on export intensity show no change [Proft, 2014; Geluebcke, 2014].

Other papers focused on cultural issues [Shenkar, 2012; Zait, Warter \& Warter, 2014] show that in the FDI literature, based on many determinants, cultural distance (CD) has had three primary thrusts. The first thrust has been to explain the foreign market investment location, the second to predict the choice of mode of entry into foreign markets, and the third application has been to account for the variable success, failure and performance of multinational enterprise (MNE) affiliates in international markets. An integrated system of determinants of FDI (especially on M\&A) is composed of seven categories of determinants: Economic, Social, Cultural, Institutional, Technological, Organizational and Commercial.

A slightly different view [Vaara et al., 2013; Hitt \& Pisano, 2003] considers that managers may use cultural differences as convenient attribution targets. The authors found that prior experience strengthens the association of failure with cultural differences. Their findings suggest that managers can 'learn' to explain failure with cultural differences, which carries with it a risk of using cultural differences as easy explanations. A similar opinion is presented by Gertsen, Soederberg and Vaara (2004). They argue that not only researchers but also the managers and employees involved in mergers have pointed to national and organizational cultural differences as major causes of integration problems. In fact, 42 


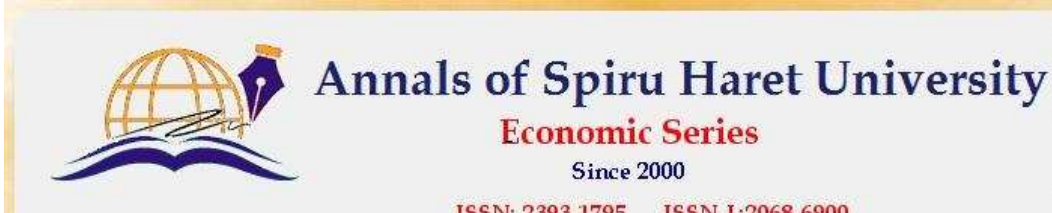

ISSN: $2393-1795$ ISSN-I.2068-6900

Issue 2/2017

culture has become an integral part of the general discussion on M\&As, and thus a core element of the social construction of the phenomenon.

An interesting opinion and a different approach [Teerikangas, Very \& Pisano, 2011; Vaara et al., 2013] reveal the roles that integration managers undertake in the post-acquisition phase with regard to capturing acquired firm value in the acquiring firm. Special attention should be focused on how managers may overemphasize the role of cultural differences and even deliberately blame cultural differences for failure. At the same time, other causes of integration problems might pass unnoticed and be left unaddressed.

Scholars explain these inconsistencies in different ways. Some claim that institutional theory can offer a comprehensive framework for understanding variations in national M\&A activity [Very et al., 2012]. Others posit that the failure to find a consistent relationship between the indicators of synergy based on relatedness and the M\&A success may stem from an overemphasis on the pre-merger stage at the expense of the negotiation process and post-merger stage, including the integration approach used during the processes of integration [Weber, Tarba \& RozenBachar, 2011].

It can be alleged that cultural diversity in organizations can be both an asset and a liability. Whether the losses associated with cultural diversity can be minimized and the gains be realized will depend likewise on the managers' ability to manage the negotiations and due diligence processes in an effective manner. This research aims to reveal how cultural diversity influences organizations' performance and the factors that help or impede organizations' performance.

For some scholars [Gertsen, Soederberg \& Vaara, 2004; Li Destri, Picone \& Mina, 2012], the emphasis on contingency and embeddedness makes it less likely that practitioners overlook relevant local linkages and the impact of national business procedures on merger performance. Thus, the key to understanding the dynamics underlying the performance of M\&A is the comparison between the amount of premium of acquisition and the value of synergies that a merger generates. The lack of understanding of culture and synergies and their appropriate evaluation results in destruction of wealth.

This review has discovered various interpretations of M\&A performance. Consequently, it can be expressed that many scholars and practitioners had significant contributions in the field. Despite a growing body of research on M\&A performance, the conclusion is that the concept of "performance" is still poorly understood. There is a need for researchers to bridge the gap between theory and 


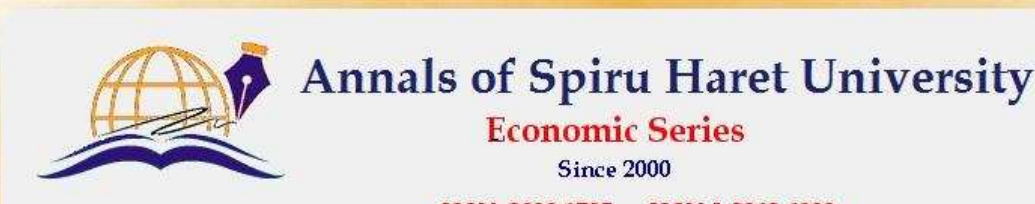

ISSN: 2393-1795 ISSN-L:2068-6900

Issue 2/2017

practice. Practitioners should encourage theoreticians to be more realistic and less reductionist in an interdisciplinary approach.

\subsection{Intercultural aspects}

Intercultural approach should remain what it is and was considered since its inception: a way to consider relating of different cultures where the company, corporation or organization performs actions, activities or business to which those connections can have consequences. There are frequent references to the cultural factor that functions as leverage, for example in the case of FDI [Zait, 2013; Rkibi, 2009]. A learning culture is included by some companies in their vision and mission, which creates the possibility to innovate, but also to adapt to the dynamic, changing environment [Zait et al., 2013].

Some studies, such as Gesteland (2012) and Connaughton, Meikle and Teerikangas (2015), define business culture as a unique set of expectations and assumptions about how to do business. Interestingly, strong corporate cultures appear to enable firms to tap into their human capital resources through organic growth, instead of relying on the purchase of other firms via M\&A.

As Hofstede et al. (2010) observe, lack of universal solutions to management and organization problems does not mean that countries cannot learn from each other. On the contrary, looking across the border is one of the most effective ways of getting new ideas for management, and organization. Accordingly, international business education should include seminars that focus on awareness of differences in cross- cultural business communication as well as on culture-specific discourse systems that have an impact on business communication [Zaidman, 2001]. In the case of an education-oriented company, more than with other types of organisations, balance and collaboration hold a greater weight in the relationship built on communication, in order to obtain qualitative results [Campeanu-Sonea, Sonea \& Bordean, 2013]. The overall pattern of connections between employees of the combined firms, the kind of personal relationship people develop with each other and shared interpretations and systems of meaning among parties are influenced by cultural differences and how they in turn impact M\&A outcomes. Employees recreate and re-form a culture or subculture by mixing elements of their existing cultural frameworks with other elements required to adapt to the M\&A process [Hajro, 2014; Van Marrewijk, 2016].

This review has found various interpretations of intercultural aspects. As scholars contend, culture is a fundamental issue not only in M\&A and cross border transactions but also in research and in everyday life in the age of globalization. 44 


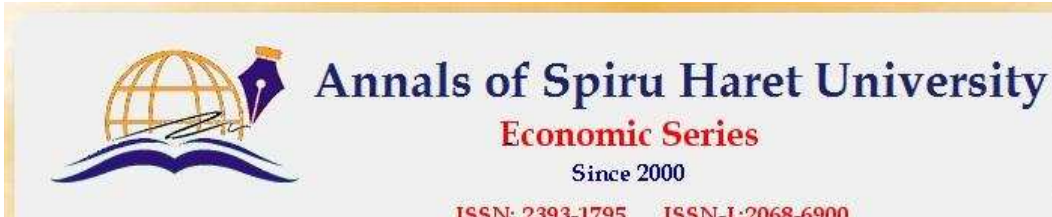

ISSN: 2393-1795 ISSN-I.2068-6900

Issue 2/2017

One of the conclusions is that any management and research approach should consider the significant role of culture. Even in domestic transactions, neglecting the cultural factor can be a huge mistake.

According to Xing et al. (2016) the level of the individual, the influences of national culture and economic ideology combine to produce a value system that is fully aligned with neither culture nor ideology. From another perspective, Lu, Huang and Bond (2016) and Jing and Bond (2015) point out that in national cultures where people's independence and personal responsibility are endorsed, individuals' decisions and actions are more likely to be decided by their own inside "cores" (i.e., values, beliefs, and orientations), or by external incentive that is consistent with their broader cultural norms. Conceptualized in this way, national culture will impact on its citizen's psychological particularities by positioning the psychological particularities of its citizenry differently with respect to the citizenry of other nations.

A quite similar approach [Reus, 2012; Hofstede et al., 2010] considers that cross-border M\&As have double-layered cultural differences of organizational and national differences, which might complicate integrating knowledge pools or can lead to a richer cluster of knowledge. For example, multinationals with a dominant home culture have a clearer set of basic values and therefore are easier to run than international organizations that lack such a common frame of reference.

Another theory on cultural differences measurement means is presented by Rosinski (2011) who emphasises the need of a vocabulary to describe cultural characteristics. The author created: The Cultural Orientations Framework (COF), an integrative framework designed to assess and compare cultures. The difference between cultures doesn't lie in the different type of dilemmas being faced but in the order in which they are taken and reconciled. Consequently, a systematic and triangulated approach to assessing cultural differences needs to be in place and communicated through the management ranks and beyond. Moreover, the archetype approach allows capturing cultural variations and certain nuances that are associated with culture within countries [Trompenaars \& Asser, 2010; Richter et al., 2016].

This paper reveals some of the most important cultural dimension measurement tools. It can be stated that despite certain approach differences, these tools, regardless their names and aggregation manner originate from the same basic human values.

It is no wonder that 'cultural differences' have become important issues in contemporary merger or acquisition deals. At the same time, working on or managing cultural differences has grown into one of the key objectives and challenges of both pre-merger and post-merger stages. A widely used construct in 


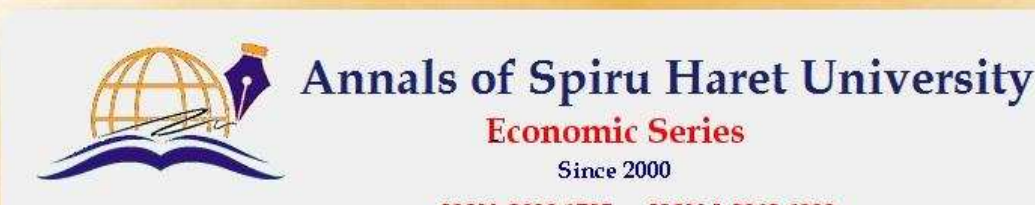

ISSN: 2393-1795 ISSN-L:2068-6900

Issue 2/2017

international business, cultural distance has been applied to foreign investment expansion, entry mode choice, and the performance of M\&As.

In search for solutions to reduce the cultural distance to the host country, [Shenkar, 2012] points out that acculturation has been defined as "changes induced in systems as a result of the diffusion of cultural elements in both directions". Certain cultures are considered attractive to other cultures, a foreign culture's perceived features may be a major reason for the preferences expressed by potential partners and host countries. Correspondingly, much of the risk associated with working in Central Europe stems from uncertainty and lack of experience, as [Zait, Warter \& Warter, 2014] reveal. This gives neighbouring countries with close historical and cultural ties to the region, such as Austria, a distinct advantage over more distant investors.

\subsection{Due diligence}

According to Boyle and Winter (2010) and Howson (2003), prior to spending considerable resources on putting together meaningful due diligence, it is imperative to ask ourselves some major questions regarding the decision under consideration due to the fact that due diligence is variously described as boring, expensive or time. What, explicitly, do we hope to achieve by the deal? What is the outcome and what are the alternatives? Why is the deal better than a greenfield operation or some other business arrangement? Multi-level due diligence and involvement of key stakeholders at every stage of the acquisition process would be helpful in overcoming many of the challenges. Furthermore, legal documents should never be viewed as a substitute for conducting formal due diligence [Caiazza \& Volpe, 2015; DePamphilis, 2011].

McDonald, Smith and Ward (2005) and Reed-Lajoux and Elson (2010) criticize the due diligence process. In spite of all its rigour and detail, it only really considers the tangible aspects of a company's valuation and neglects "soft" information such as conflict and culture. The nature of each due diligence finding dictates whether it is best addressed before or after the closing. Navigating the raging waters of a fast flowing river requires the expertise of a due diligence team to tame the rapids and torrents zigzagging across the river, and at times against its natural flow and directions. These rapids and torrents represent the frequently risks that are plentiful in an M\&A landscape [Gole \& Hilger, 2009; Ho \& Koh, 2016].This calls for a change in the multi-level due-diligence process conducted by firms before an acquisition, factoring in management's motivations, evaluation of risks and ability to overcome specific challenges [Caiazza \& Volpe, 2015; Howson, 46 


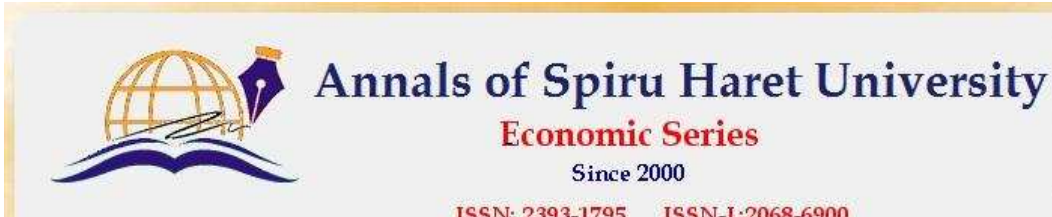

ISSN: $2393-1795$ ISSN-I.2068-6900

Issue $2 / 2017$

2006]. In other words, the better the due diligence, the more an acquirer knows about the target firm and therefore the more it knows about the immediate risks it is taking on.

Back in 1997, an author [Carleton, 1997] mentioned that regardless of what models we choose or what methodology we employ, cultural due diligence is coming, and soon. It won't be accountants or lawyers who conduct the audits; it will be human resources (HR) people. The question is: Will we be ready?. Today's M\&A success rate hovers around 30 to 40 percent, with clashing cultures cited as at least a contributing factor in most cases. And yet, despite the lessons of history, many due diligence teams glance past the topic, preferring instead to focus on items that can be easily quantified [Recardo \& Toterhi, 2014; Gomes et al., 2012].

Consistent with the Stachowicz-Stanusch (2009) paper, a study by Berkman (2013) contends that in the context of a merger of two businesses, one of the intangible issues directly affecting the success of the transaction down the road is whether the business cultures mesh well. The cultural due diligence process can avoid a merger disaster. In a reflection on cultural due diligence opportunity, Carleton and Lineberry (2004) and Rosenbloom (2002) consider CDD should be viewed as a mandatory step to maximize post-merger or acquisition organizational effectiveness and profitability. According to them, CDD can determine the extent to which change can or cannot occur smoothly within a firm.

Other authors [Reed-Lajoux \& Elson, 2010; Gleich et al., 2010; Galpin \& Herndon, 2014] also support the need for CDD. They reveal that cultural due diligence includes research into what the people in an organization routinely believe, think, and do, including attitudes and mental processes, behaviour, norms, symbols, and history. Moreover, due diligence is a key ingredient both of successful negotiation and of post-deal integration. Cultural due diligence can provide a picture of where two companies converge or diverge on such aspects as leadership, communication, performance management, and so on.

In their comprehensive analyses, Carleton (1997) and Rottig (2013) underscore that the point of cultural due diligence is not to discourage mergers between companies whose cultures happen to differ-most culture-clash problems can be (and have been) handled successfully. Rather, the point is to have a strategy to manage these differences, just as companies do with divergent financial procedures or information systems. CDD, as a crucial first step in the socio-cultural integration process, involves a systematic analysis of the cultural particularities of a possible merger or acquisition partner in order to determine the cultural compatibility between the involved organizations. 


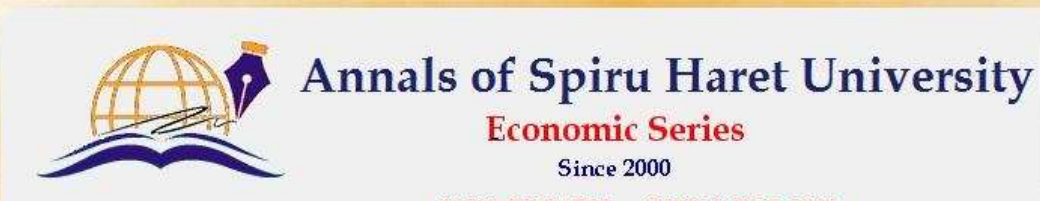

ISSN: 2393-1795 ISSN-L:2068-6900

Issue 2/2017

Focusing on the practical approach to cultural due diligence, Spedding (2008) and Warter and Warter (2014) reveal that, although most of the experts and practitioners point to the importance of due diligence of $\mathrm{M} \& \mathrm{~A}$, in many cases there is not an appropriate practical approach. Furthermore, CDD has to include leadership, change management, decision-making, cultural descriptions etc. Unfortunately, many companies, although conducting systematic financial analyses in the pre-M\&A stage, neglect to examine cultural issues during the cultural due diligence process. This shows the lack of importance companies attach to the cultural integration process prior to a merger or acquisition.

Other authors [Reed-Lajoux \& Elson, 2010; Gleich et al., 2010] show that approaches to cultural due diligence fall into four general categories: integrating cultural criteria into the pre-merger discussions, staffing and preparing the due diligence team with an eye toward cultural issues, adding cultural criteria to due diligence data collection, and using formal tools to assess culture fit.

Integration teams should conduct a thorough cultural due diligence on the other company's culture and also should investigate own company, culture and standards in order to determine if the companies fit. The findings show a lack of consensus about the CDD content, a relatively new area of the due diligence process, and about the depth of this process. It can be remarked, though, that the overall opinion is that CDD has a strong influence on M\&A performance.

\section{Research methods}

\subsection{Research setting}

The study took a quantitative approach. The most appropriate way to reach the research goals was to develop a questionnaire. The subjects of this research were managers involved in the pre-M\&A stage.

The quantitative survey approach follows from the post-positivist ontological and epistemological bases of this study. An important advantage of the quantitative survey method is that looking across numerous cases makes it possible to generalize results.

This research is more suitable to well-defined research questions. Open questions are very time consuming. Close-ended questions also avoided poorquality responses. Considering that the subjects of the research were mainly middle and top managers, the response rate to open questions could be very low and the results not very convincing.

This study used newly generated numerical data. Numerical data might seem inadequate for a study based on perceptions but the levels of perception were 48 

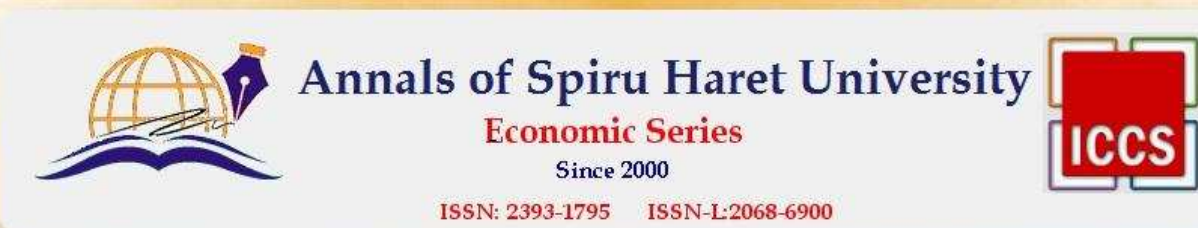

SSN: 2393-1795 ISSN-I.2068-6900

Issue $2 / 2017$

translated into numerical data using the Likert scale. A 5-point Likert scale was used because it's easier for the respondent and less time consuming than a 7-point Osgood scale.

This research is based on the following question:

How important is it to investigate soft risks during due diligence?

\begin{tabular}{|llllll|}
\hline Not at all & \multicolumn{7}{l|}{ Very important } \\
\hline Communication & 1 & 2 & 3 & 4 & 5 \\
\hline Organizational culture & 1 & 2 & 3 & 4 & 5 \\
\hline National culture & 1 & 2 & 3 & 4 & 5 \\
\hline Professional culture & 1 & 2 & 3 & 4 & 5 \\
\hline
\end{tabular}

Data collection was held 1 to 6 years after the merger or acquisition date. This delay allowed the analysis of the integration process in a meaningful way. At the same it was not too long to create problems concerning the retrospective sense making.

The data collection process was performed in absence of an interviewer. The data collection activities were done remotely. From the basic methods available for data collection in surveys (telephone survey, personal interviews, and mail survey), the mail survey method was chosen due to several reasons:

- the cost was lower;

- it offered the opportunity to reach more respondents in a wider geographical area;

- it was less time consuming for the respondents in key positions;

- it avoided interviewer bias, consequently increasing the reliability.

A special concern was to minimize the negative reaction of the respondents by using appropriate questions and question wording. Special attention was paid to other characteristics of the survey items: the time reference, social desirability, and saliency or centrality.

Clear instructions about the requested details in the mail survey were provided. The questionnaire was developed considering the usefulness of responses, the chance of getting the expected data and the readiness of the respondents to accurately answer the questions.

A careful examination was conducted in order to reduce the non-sampling errors associated with validity, specification, and measurement reflected in the 


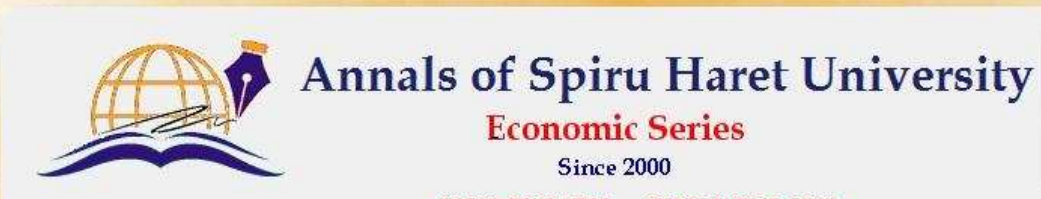

ISSN: 2393-1795 ISSN-L:2068-6900

\section{Issue 2/2017}

following questions: "What can be measured to reflect the concept?", "How well does the measurement reflect the concept?", "How well does the question capture the desired measurement?", "How well does the response match the intent of the question?".

The questionnaire was sent in English because people involved in the preM\&A stage have a high level of this language.

\subsection{Data Gathering and Analysis}

The participants were senior managers who experienced first-hand the process of intercultural due diligence, negotiation and decision-making. All participants (154) were anonymous to each other in order to get their own ideas, answers, and experiences when responding to the questionnaire.

The selection of the sample was a question of balancing accuracy against cost and feasibility. Non-probabilistic sampling was used and therefore it is a potential for bias and inaccuracies in generalizing to a larger population.

The sample companies were selected using secondary data provided by the main financial magazines in the analysed countries. The main target countries were Romania and Eastern European countries (52 companies from Poland, Bulgaria, Czech Republic, and Hungary). The sample companies included also companies from other countries (39 companies from Austria, Netherlands, USA, Israel, Canada, France, Germany, Switzerland, Pakistan, Cyprus, South Africa, Belgium, Sweden, Japan, and Brazil). The companies are from various industries like: Agriculture, Chemical industry, Construction industry, Electronics industry, Food industry, Healthcare industry, Plastics industry, Textile industry, Software industry. The selection was carried out according to the following criteria:

1 . The acquired company or one of the participants in merger was a local company from the selected countries.

2. Management buy-outs and purely financial acquisitions were excluded.

3. Regarding acquisitions, there were considered only cases in which the acquiring party had gained a majority stake (over 50\%) of the acquired firm.

4. Only mergers/acquisitions where the minimum turnover of the two parties involved exceeded EUR 1 million were included.

Participation in the study was solicited through a number of direct and indirect channels to individuals who had the above-mentioned profile. These channels included:

- friends and colleagues; 


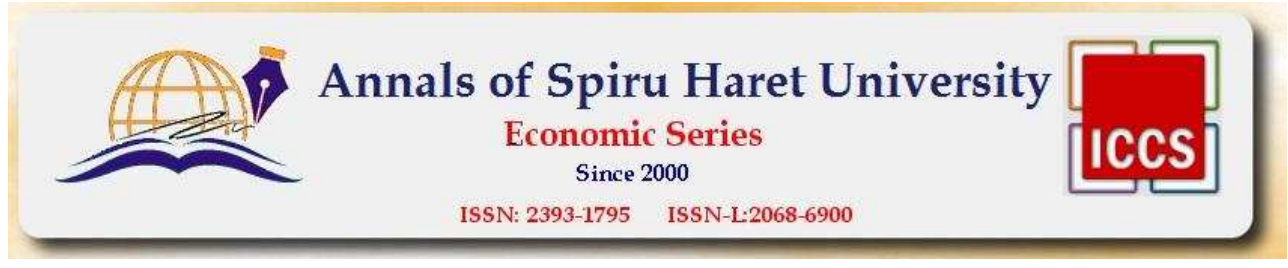

Issue $2 / 2017$

- referrals from friends and colleagues;

- postings on M\&A related web forums and electronic distribution lists;

- direct emails to members of M\&A related communities of interest;

- email referrals from individuals who filled the questionnaire.

The questionnaire has been made available to the general public by placing it on Dropbox.

In addition, the following Social Networking Sites for Scholars and Business Professionals were used: Research Gate, Academia.edu, LinkedIn, and Facebook.

Special attention was paid to the errors that occur due to the nature of the research design and the precision of execution (systematic errors). Very significant for the research were both broad categories: administrative errors and respondent errors. Sample error or bias (results of a sample show consistent deviation, in a direction away from the true value of the population parameter) was also examined. The mail survey raised the issue of significance of instrument-associated errors due to poor questionnaire design, improper selection of samples, etc.

Regarding ethical assurance, this study was designed to comply with the standards for conducting research with human participants. Provisions were made for the participants to receive a copy after the study will be completed. The privacy of the respondents was respected by the exclusion of questions that participants may have considered personal or private. The respondents were not asked about their religion, marital status, etc.

A cross-sectional survey was conducted because it focuses on collecting data about current attitudes, opinions, or beliefs relating to the national, organizational and professional culture. This kind of survey was more representative of the population and the research objectives did not include repeated research over a period of time. The data is based on a single data collection round. The response rate for the survey was rather small. However, in mergers and acquisitions research, the sensitive nature of the operations restricts the willingness of managers to comment on the process.

The main preoccupations after the data collection concerned the internal validity, external validity and reliability. Internal validity is the extent to which results can be interpreted accurately. During data-collection, several measures to improve the internal validity of the questionnaire were taken. External validity is defined as the extent to which the results can be generalized to populations and conditions. The response rates seemed adequate to enable generalizations. Reliability is the degree to which the observed variable is free of measurement 

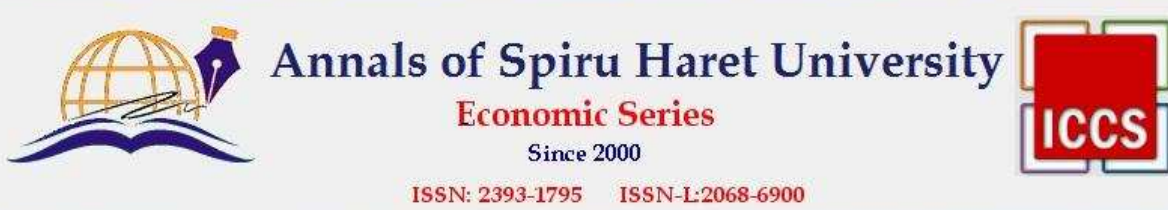

Issue 2/2017

error. Several precautions were taken to increase the reliability of the measures. Special attention was paid to sampling error and non-sampling error.

Received responses were downloaded into an Excel spreadsheet. Statistical analyses were performed on the data using Statistical Package for the Social Science (SPSS 20.0).

The most important steps in data preparation for the research were analysis, validation, editing and data cleaning.

Given the design of the questionnaire missing values were not a central issue but still there were missing values from some respondents. Incorrect values were an issue of lesser importance.

\section{Findings and Discussion}

\subsection{Results}

Table no. 1 presents the factors and corresponding items for Importance of soft risks investigation during due diligence.

Table no. 1. Factors and corresponding items for Importance of soft risks investigation during due diligence

\begin{tabular}{|l|l|l|l|l|}
\hline Item number & \multicolumn{1}{|c|}{ Item name } & Item code & Factor & Factor name \\
\hline 1. & Communication & c & F1 & Culture \\
\hline 2. & Organizational culture & oc & F1 & Culture \\
\hline 3. & National culture & nc & F1 & Culture \\
\hline 4. & Professional culture & pc & F1 & Culture \\
\hline
\end{tabular}

Table no. 2 presents KMO and Bartlett's Test results for Importance of soft risks investigation during due diligence. It can be observed that the overall value for the "Measure of Sampling Adequacy" has a suitable value at 0.813, and "Bartlett's Test of Sphericity" has an associated P value (Sig. in the table) of $<0.001$ as by default SPSS reports $p$ values of less than 0.001 as 0.000 . These results indicate that a valid factor analysis can be performed. 
Issue 2/2017

Table no. 2. KMO and Bartlett's Test for Importance of soft risks investigation during due diligence

\begin{tabular}{|c|c|r|}
\hline \multicolumn{2}{|c|}{ KMO Measure of Sampling Adequacy. } & 0.813 \\
\hline Bartlett's Test & Approx. Chi-Square & 95.354 \\
\cline { 2 - 3 } & df & 6 \\
\cline { 2 - 3 } & Sig. & 0 \\
\hline
\end{tabular}

Table no. 3 presents Total Variance Explained results for Importance of soft risks investigation during due diligence. In the table can be noticed that one component was extracted. The scree plot is displaying the same data visually.

Table no. 3. Total Variance Explained for Importance of soft risks investigation during due diligence

\begin{tabular}{|c|c|c|c|c|c|c|}
\hline Co & \multicolumn{3}{|c|}{ Initial Eigenvalues } & \multicolumn{3}{|c|}{ Extraction Sums of Squared Loadings } \\
\hline $\begin{array}{c}\mathrm{mp} \\
\text { one } \\
\mathrm{nt}\end{array}$ & Total & $\begin{array}{c}\% \text { of } \\
\text { Variance }\end{array}$ & Cumulative $\%$ & Total & $\begin{array}{c}\% \text { of } \\
\text { Variance }\end{array}$ & Cumulative \% \\
\hline 1 & 2.860 & 71.489 & 71.489 & 2.860 & 71.489 & 71.489 \\
\hline 2 & .465 & 11.630 & 83.119 & & & \\
\hline 3 & .423 & 10.578 & 93.698 & & & \\
\hline 4 & .252 & 6.302 & 100.000 & & & \\
\hline
\end{tabular}

Table no. 3 also shows the importance of each of the principal components. Only the first has eigenvalue over 1.00 , and this explains over $71 \%$ of the total variability in the data. This means that a one factor solution will be acceptable.

The middle part of the table shows the eigen-values and percentage of variance explained for just the factor of the initial solution that is considered important. In the right hand part of the table, can be found the eigen-value and percentage of variance explained for the rotated factor

The unrotated factor loadings show the expected pattern, with high positive loadings on the first factor (Figure no. 1). 
Issue $2 / 2017$

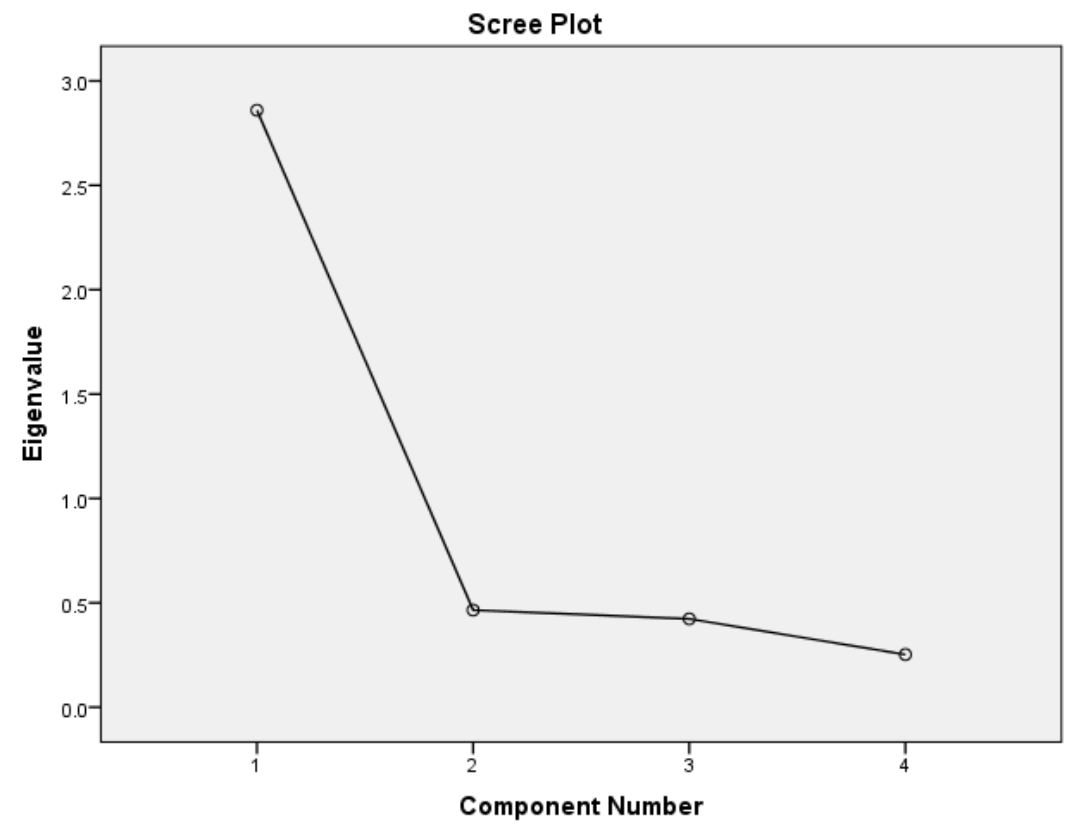

Figure no. 1. Scree plot for Importance of soft risks investigation during due diligence

Communication, Organizational culture, National culture and Professional culture (1, 2, 3 and 4) all have high positive loadings on the factor.

It is reasonable to identify the factor (F1) as "Culture".

As one factor was extracted, we have one factor equation.

Table no. 4 presents the Component Score Coefficient Matrix for Importance of soft risks investigation during due diligence. 
Issue $2 / 2017$

Table no. 4. Component Score Coefficient Matrix for Importance of soft risks investigation during due diligence

\begin{tabular}{|l|c|}
\hline & $\begin{array}{c}\text { Component } \\
\text { Score }\end{array}$ \\
\hline 1 & 0.310 \\
\hline 2 & 0.303 \\
\hline 3 & 0.288 \\
\hline 4 & 0.280 \\
\hline
\end{tabular}

Using the values from Table no. 4, the equation is:

$\mathbf{F 1}=0.310 * \mathbf{c}+0.303 * \mathbf{o c}+0.288 * \mathbf{n c}+0.280 * \mathbf{p c}$

The Saved Factor scores have been added to the data. These are standardized scores, obtained by applying the rotated factor loadings to the standardized score of each participant on each of the variables.

\subsection{Discussion on empirical findings}

Using Factor Analysis it was extracted a factor for this dimension. It corresponds to 4 basic items.

The dimension Importance of soft risks investigation during due diligence is essential for the content of the Cultural Due Diligence. This study allowed furthering the understanding on the issues that need more attention from practitioners during the pre-M\&A investigation. The analysis of the CDD construct is also meant to unravel the biases of some scholarly research.

The extracted factor Culture represents the core of the Cultural Due Diligence.

The basic items (Communication, Organizational culture, National culture, and Professional culture) could be ranked according to the perceptions of the respondents. The most important is: Communication, while Professional culture is considered the least important.

The resulted formula is a tool to be used for measuring the perception of respondents on the content of Cultural Due diligence. 
Issue 2/2017

\section{Conclusions and suggestions for future research}

\subsection{Limitations}

The main limitations of this study are:

- The research is based on collected data that represents the perception of the sample population, as opposed to an objective measurement of data.

- The population of this study is composed of senior managers who experienced first-hand the process of intercultural due diligence, negotiation and decision-making. This study is not restricted to a specific industry or company profile.

- The questionnaire used in this research relates to only some facets of the pre-M\&A activities. The results and interpretation of this research are limited to these facets.

- The selected countries sample populations is not a probability sample because the sample is voluntary and hence it may have a self-selection bias.

- The emotional involvement of the respondents might cause exaggeration of facts.

\subsection{Implications}

M\&A is one of the major business phenomena in the past decades and it will continue to be in the future. In the last twenty years, there has been a growing body of research on M\&A performance and on the success of mergers and acquisitions (M\&As). Notwithstanding the foregoing, the key determinants for success remain poorly understood.

The core of this work is the pre-M\&A stage. The aim is to throw light on the cultural issues related to due diligence.

This study makes a contribution to the field of intercultural issues in M\&A by integrating research on national, organizational and professional culture, into a theory of cultural due diligence content and outcome. It attempted to investigate not only the outcomes but the perception on the process of cultural due diligence.

The common underlying belief is that intercultural aspects have a strong influence on M\&A performance. A significant deficiency is the almost complete separation between national, corporate and professional culture. Ergo researchers have to bridge the gap between theory and practice and to be more realistic and less reductionist in an interdisciplinary approach.

The dimension Importance of soft risks investigation during due diligence is essential for the content of the Cultural Due Diligence. This study approached in 


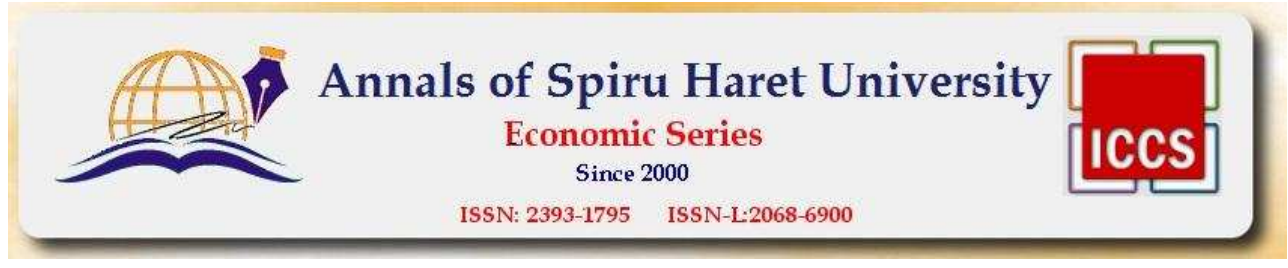

Issue $2 / 2017$

depth the issues that need more attention from practitioners during the pre-M\&A investigation.

The extracted factor Culture represents the core of the Cultural Due Diligence.

The basic items (Communication, Organizational culture, National culture, and Professional culture) were rated in compliance with the perceptions of the M\&A practitioners. Consequently the most important is: Communication, while Professional culture is considered the least important.

The resulted formula is a tool to be used for measuring the perception of respondents on the content of Cultural Due diligence.

Cultural Due Diligence (CDD) intends to offer data enough detailed to determine potential areas of culture clash. The impact of cultural diversity rest on the managers' ability to manage the negotiations and due diligence processes in an effective manner.

Given the findings of this study which suggest a combined effect of national, organizational and professional cultures, future research may need to examine the dynamic nature of a wider spectrum of cultural influences on M\&A perceptions. Such exploration would lead to a more refined understanding of the cultural issues in M\&A and how organizations can benefit from such a shift.

\section{References}

1. Angwin, Duncan N., and Maureen Meadows. "New Integration Strategies for PostAcquisition Management.” Long Range Planning 48, no. 4 (2014): 235-51.

2. Berkman, J.W. Due Diligence and the Business Transaction: Getting a Deal Done (New-York: Apress, 2013), 292.

3. Bertrand, Olivier, and Laurence Capron. "Productivity enhancement at home via crossborder acquisitions: The roles of learning and contemporaneous domestic investments." Strategic Management Journal 36, no. 5 (2015): 640-58.

4. Boyle, James, and Matthew Winter. "A different toolbox for M\&A due diligence in China.” Thunderbird International Business Review 52, no. 1 (2010): 55-59.

5. Caiazza, Rosa, and Tiziana Volpe. "M\&A process: a literature review and research agenda.” Business Process Management Journal 21, no. 1 (2015): 205-20.

6. Campeanu-Sonea, Eugenia, Adrian Sonea, and Ovidiu Niculae Bordean. "Communication and Multicultural Higher Education in Economics and Business Management." In 7th International Management Conference: New Management for the New Economy, 501-09. Proceedings. Bucharest, Romania.

7. Carleton, J.R. 'Cultural Due Diligence.” Training 34, no. 11 (1997): 57-75. 


\section{Issue 2/2017}

8. Carleton, J. Robert, and Claude S. Lineberry. Achieving Post-Merger Success: A Stakeholder's Guide to Cultural Due Diligence, Assessment, and Integration (San Francisco: Pfeiffer, 2004), 240.

9. Connaughton, John, Jim Meikle, and Satu Teerikangas. "Mergers, acquisitions and the evolution of construction professional services firms." Construction Management and Economics 33, no. 2 (2015): 146-59.

10. DePamphilis, Donald M. Mergers and acquisitions basics: negotiation and deal structuring (Amsterdam; Heidelberg: Elsevier, 2011), 240.

11. Galpin, T.J. and M. Herndon. The Complete Guide to Mergers and Acquisitions Process Tools to Support M\&A Integration at Every Level (San Francisco, CA: Jossey-Bass, 2014), 480.

12. Geluebcke, John P. Weche. "The impact of foreign takeovers: comparative evidence from foreign and domestic acquisitions in Germany." Applied Economics 47, no. 8 (2014): 739-55.

13. Gertsen, Martine Cardel, Anne-Marie Soederberg, and Eero Vaara. "CULTURAL CHANGE PROCESSES IN MERGERS - A social constructionist perspective." http://openarchive.cbs.dk/bitstream/handle/10398/6942/wp38.pdf?sequence=1, 2004.

14. Gesteland, Richard R. Cross-cultural business behaviour: a guide for global management (Copenhagen: Copenhagen Business School Press, 2012), 399.

15. Gleich, Ronald, Gordana Kierans, and Thomas Hasselbach. Value in due diligence: contemporary strategies for merger and acquisition success (Farnham, England: Gower, 2010), 216.

16. Gole, William J. and Paul J. Hilger. Due Diligence: An M\&A Value Creation Approach (Hoboken, New Jersey: John Wiley \& Sons, 2009), 281.

17. Gomes, Emanuel, Duncan N. Angwin, Emmanuel Peter, and Kamel Mellahi. "HRM issues and outcomes in African mergers and acquisitions: a study of the Nigerian banking sector". The International Journal of Human Resource Management 23, no.14 (2012): 2874-2900.

18. Gomes, Emanuel, Duncan N. Angwin, Yaakov Weber, and Shlomo Yedidia Tarba. "Critical Success Factors through the Mergers and Acquisitions Process: Revealing Pre- and Post-M\&A Connections for Improved Performance". Thunderbird International Business Review 55, no. 1 (2013): 13-35.

19. Gomes, Emanuel, Bradley R. Barnes, and Tehmina Mahmood. "A 22 year review of strategic alliance research in the leading management journals." International Business Review 25, no. 1 (2016): 15-27.

20. Hajro, Aida. "Cultural influences and the mediating role of socio-cultural integration processes on the performance of cross-border mergers and acquisitions." The International Journal of Human Resource Management 26, no. 2 (2014): 192-215. 


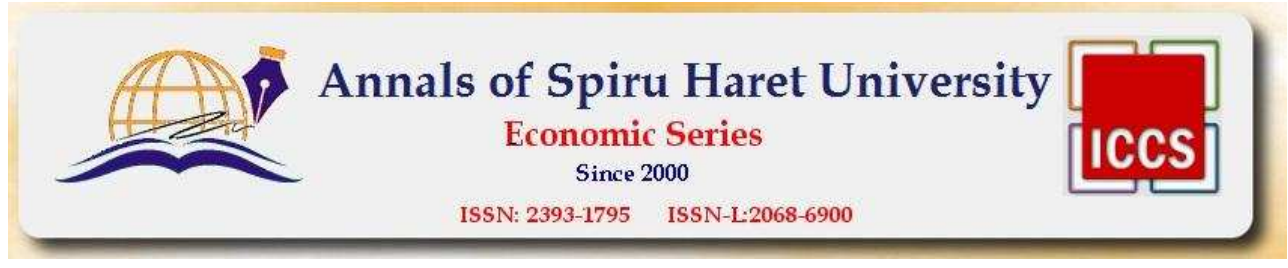

Issue $2 / 2017$

21. Hitt, Michael A., and Vincenzo Pisano. "The Cross-Border Merger and Acquisition Strategy: A Research Perspective." Management Research: Journal of the Iberoamerican Academy of Management 1, no. 2 (2003): 133-44.

22. Ho, Chyekok. and ChinSeng Koh. HR DUE DILIGENCE: mergers and acquisitions in China. Cambridge, UK: CHANDOS Publishing, 2016.

23. Hofstede, Geert H., Gert Jan. Hofstede, and Michael Minkov. Cultures and organizations: software of the mind: intercultural cooperation and its importance for survival (New York: McGraw-Hill, 2010), 576.

24. Howson, Peter. Due diligence: the critical stage in mergers and acquisitions (Aldershot: Gower Pub., 2003), 286.

25. Howson, Peter. Commercial due diligence: the key to understanding value in an acquisition (Aldershot: Gover, 2006), 416.

26. Jing, Y., and M. H. Bond. "Sources for Trusting Most People: How National Goals for Socializing Children Promote the Contributions Made by Trust of the In-Group and the Out-Group to Non-Specific Trust." Journal of Cross-Cultural Psychology 46, no. 2 (2015): 191-210.

27. Li Destri, Arabella Mocciaro, Pasquale Massimo Picone, and Anna Minà. "From 'Strategic Fit' to Synergy Evaluation in M\&A Deals". Caspian Journal of Applied Sciences Research 1, no.12 (2012): 25-38. SSRN: https://ssrn.com/abstract=2164696

28. Lu, Q., X. Huang, and M. H. Bond. "Culture and the Working Life: Predicting the Relative Centrality of Work Across Life Domains for Employed Persons." Journal of Cross-Cultural Psychology 47, no. 2 (2016): 277-93.

29. Marrewijk, Alfons Van. "Conflicting Subcultures in Mergers and Acquisitions: a Longitudinal Study of Integrating a Radical Internet Firm into a Bureaucratic Telecoms Firm." British Journal of Management 27, no. 2 (2016): 338-54.

30. McDonald, Malcolm, Brian Smith, and Keith Ward.Marketing due diligence: reconnecting strategy to share price. Oxford: Butterworth-Heinemann, 2005.

31. Proft, Carolin. The speed of human and task integration in mergers and acquisitions: human integration as basis for task integration (Wiesbaden: Springer Gabler, 2014), 107.

32. Recardo, Ronald J., and Tim Toterhi. "The Secrets of Operational and Organizational Due Diligence." Global Business and Organizational Excellence 33, no. 2 (2014): 14-30.

33. Reed-Lajoux, Alexandra, and Charles Elson. The art of $M \& A$ : due diligence: navigating critical steps and uncovering crucial data (Maidenhead: McGraw-Hill, 2010), 480.

34. Reus, Taco H. "A Knowledge-Based View of Mergers and Acquisitions Revisited: Absorptive Capacity and Combinative Capability." Advances in Mergers and Acquisitions, 2012, 69-88. 


\section{Issue 2/2017}

35. Richter, Nicole Franziska, Sven Hauff, Christopher Schlaegel, Siegfried Gudergan, Christian M. Ringle, and Marjaana Gunkel. "Using Cultural Archetypes in Crosscultural Management Studies." Journal of International Management 22, no. 1 (2016): 63-83.

36. Rkibi, Tawfiq. "Cunoaşterea distanţelor culturale generează avantaj concurenţial?". Management intercultural XI, no.19 (2009): 2-38.

37. Rosenbloom, Arthur H. Due diligence for global deal making: the definitive guide to cross-border mergers and acquisitions, joint ventures, financings, and strategic alliances (Princeton: Bloomberg Press, 2002), 343.

38. Rosinski, Philippe. "Global Coaching for Organizational Development." International Journal of Coaching in Organizations 8, no. 2 (2011): 49-66.

39. Rottig, Daniel. "A Marriage Metaphor Model for Sociocultural Integration in International Mergers and Acquisitions." Thunderbird International Business Review 55, no. 4 (2013): 439-51.

40. Sahoo, Pravakar, Ranjan Kumar Dash, and Geenthanjali Nataraj. Foreign direct investment in South Asia: policy, impact, determinants and challenges (New Delhi: Springer, 2014), 357.

41. Shenkar, Oded. "Cultural distance revisited: Towards a more rigorous conceptualization and measurement of cultural differences." Journal of International Business Studies 43, no. 1 (2012): 1-11.

42. Spedding, Linda S. The due diligence handbook: corporate governance, risk management and business planning (Amsterdam: Elsevier, 2008), 752.

43. Stachowicz-Stanusch, A. "Culture Due Diligence based on HP/Compaq Merger case study”. Journal of Intercultural Management 1, no.1 (2009): 64-81.

44. Teerikangas, Satu, Philippe Véry, and Vincenzo Pisano. "Integration managers' valuecapturing roles and acquisition performance." Human Resource Management 50, no. 5 (2011): 651-83.

45. Trompenaars, Alfons, and Maarten Nijhoff. Asser. The global M\&A tango: Crosscultural Dimensions of Mergers and Acquisitions. New York: McGraw-Hill, 2010.

46. Vaara, Eero, Paulina Junni, Riikka M. Sarala, Mats Ehrnrooth, and Alexei Koveshnikov. "Attributional tendencies in cultural explanations of M\&A performance.” Strategic Management Journal 35, no. 9 (2013): 1302-317.

47. Very, Philippe, Emmanuel Metais, Serigne Lo, and Pierre-Guy Hourquet. "Can We Predict M\&A Activity?” Advances in Mergers and Acquisitions, 2012, 1-32.

48. Warter, Iulian, and Liviu Warter. "Latest Trends in Mergers and Acquisitions Research. The New Pattern of Globalization." Bulletin of the Polytechnic Institute of Iasi, LX (LXIV), no. 2 (2014): 25-43.

49. Warter, Liviu, and Iulian Warter. "Can Mergers And Acquisitions Improve Banking Industry?” Edited by Angela Roman, Sorin Gabriel Anton, and Irina Bilan. In Euro 
and the European banking system: evolutions and challenges, 377-86. Iasi, Romania: Editura Universitatii “Alexandru Ioan Cuza, 2015.

50. Weber, Yaakov, Dalia Rachman-Moore, and Shlomo Yedidia Tarba. "HR practices during post-merger conflict and merger performance." International Journal of Cross Cultural Management 12, no. 1 (2012): 73-99. d

51. Weber, Yaakov, Shlomo Y. Tarba, and Arie Reichel. "A Model of the Influence of Culture on Integration Approaches and International Mergers and Acquisitions Performance.” International Studies of Management and Organization 41, no. 3 (2011): 9-24.

52. Weber, Yaakov, Shlomo Y. Tarba, and Arie Reichel. "A Model of the Influence of Culture on Integration Approaches and International Mergers and Acquisitions Performance." International Studies of Management and Organization 41, no. 3 (2011): 9-24.

53. Weber, Yaakov, Shlomo Yedidia Tarba, and Ziva Rozen Bachar. "Mergers and acquisitions performance paradox: the mediating role of integration approach.” European J. of International Management 5, no. 4 (2011): 373.

54. Xing, Yijun, Yipeng Liu, Shlomo Yedidia Tarba, and Cary L. Cooper. "Intercultural influences on managing African employees of Chinese firms in Africa: Chinese managers' HRM practices." International Business Review 25, no. 1 (2016): 28-41.

55. Zaidman, N. "Cultural Codes and Languages Strategies in Business Communication: Interactions between Israeli and Indian Business people." Management Communication Quarterly 14, no. 3 (2001): 408-41.

56.Zait, Dumitru. Diagnostic intercultural. Competitivitate organizaţională prin mixare culturală şi despre creşterea performanţei manageriale prin sinergie interculturală (Iasi: Editura Universitatii “Al. I. Cuza”, 2013), 358.

57. Zait, Dumitru, Angelica Nicoleta Onea, Ruxandra Ciulu, and Maria Tatarusanu. “An empirical perspective on culture - corporate social responsibility relationship.” Cross-Cultural Management Journal XV, no. 2(4) (2013): 67-76.

58. Zait, Dumitru, Liviu Warter, and Iulian Warter. "Cross-Cultural Incentives for the FDI.” Cross-Cultural Management Journal XVI, no. 1(30) (2014): 798-811.

59. Zhang, Jiali, Mohammad Faisal Ahammad, Shlomo Tarba, Cary L. Cooper, Keith W. Glaister, and Jinmin Wang. "The effect of leadership style on talent retention during Merger and Acquisition integration: evidence from China." The International Journal of Human Resource Management 26, no. 7 (2014): 1021-050.

60. Merger and Acquisition integration: evidence from China." The International Journal of Human Resource Management 26, no. 7 (2014): 1021-050. 
